\title{
Design and Strength Analysis of FSAE Suspension
}

\author{
Li Sun ${ }^{*}, 1,2$ Zhao Deng ${ }^{1}$ and Qing Zhang ${ }^{1}$ \\ ${ }^{I}$ School of Traffic Engineering, Huaiyin Institute of Technology, Huai'an 223003, P.R. China \\ ${ }^{2}$ School of Mechanical Engineering, Southeast University, Nan Jing 210096, P.R. China
}

\begin{abstract}
China FSAE race introduced formula racing gradually in the university campus in order to make FSAE racing have better ride comfort, handling and stability. Design and strength analysis of FSAE suspension were also proposed. Firstly, according to the whole layout of FSAE racing, the suspension mode was selected, both front and rear suspension were unequal push rod type double wishbone independent suspensions. Secondly, the main parameters and the orientation structure of the front and rear suspension were preliminarily designed. The wheels alignment parameters were selected with all kinds of stiffness, damping coefficient, followed by cross arm length calculation. According to the design parameters, suitable rim and shock absorber were chosen to determine the structure of the suspension's main components . Thirdly, the front and rear suspension models were set up by the SolidWorks 3D software. Finally, the analysis of static stress on the main components of FSAE racing using the simulation module was performed to form the car suspension system so that it meets the design requirements of the FSAE regulations. This paper could provide references for the real vehicle development.
\end{abstract}

Keywords: FSAE, design, strength analysis, suspension.

\section{INTRODUCTION}

FSAE racing is a sport with global influence. It is a college student design competition known as the "academic F1". The suspension system is the device connecting the body with wheels. When the body has irrelative motion between the wheels, the motion is constrained by the suspension with all kinds of forces and moments between the wheels and the ground. The design of the suspension system is an important part of the overall vehicle design, which determines the performance of the racing car.

The car suspension kinematics research started earlier in developed countries. Brazil Sao Paulo University in 2005 designed FSAE racing suspension by using the push rod unequal wishbone for both front and rear suspensions, and a multi-body dynamics model was established to analyze the kinematics and dynamics. In 2008, Greece's Aristotle University designed the first FSAE race car with front and rear suspension by placing an unequal double wishbone type. The selection principles of the roll center were given and the effects of front wheel alignment parameters on the handling stability were discussed. In order to avoid the cross arm bending, push rod was directly hinged on the steering knuckle.

In recent years, China has also begun research on college student formula racing. In 2011, South China University of Technology based on the optimization analysis platform ADAMS/Insight, determined the design variables, the design

*Address correspondence to this author at the School of Traffic Engineering, Huaiyin Insititute of Technology, Huai'an 223003, P.R. China;

Tel: +8613505235416; Fax: +86-0517-83559167; E-mail: sunli0124@163.com goal, the goal function, and constraint conditions. The experimental design and multi-objective optimization design were tested on the front and the rear suspension system, respectively $[1,2]$. In June the same year, the Harbin Institute of Technology's Li Man did the static and modal analysis of the suspension's lower arm for FSAE racing [3, 4]. In 2013, Beijing Information Science and Technology University's Jiang Liman adopted the method to combine the analysis with test, taking the finite element analysis software Hyper Works and LS-DYNA as the calculation tools, the DASP as modal test analysis system and e-DAQ as stress test data acquisition system, to complete more comprehensive static and dynamic characteristics analysis and structural optimizations $[5,6]$.

Above all, suspension design is a complex process, the type of suspension was determined by the comparison of different characteristics of the suspensions, and a number of parameters were designed according to the parameter selection and calculation. Following this, the parts of the suspension were designed and assembled. The question is to determine what will ensure the feasibility and reliability of the design of the suspension used in the racing car?

\section{FSAE RACING CAR SUSPENSION DESIGN}

According to the requirements of China college student formula race, the race car suspension must have the shock absorber, the suspension travel should not be less than 25.4 $\mathrm{mm}$ in the case of a racer, and all the connection points must be directly or indirectly visible. Therefore, the FSAE car suspension design should meet the following requirements:

(1) It must have the appropriate attenuation vibration ability. 
(2) It must ensure the car has good handling and stability performance;

(3) It must be light but strong;

(4) It should guarantee easy operation and control for the driver;

(5) It must have convenient installation and easy adjustment.

In view of the flexibility and good motion characteristics of the double wishbone layout, the unequal length independent suspension is adopted.

FSAE racing requires that the rim diameter is not less than $203.2 \mathrm{~mm}$, while the commonly used rim sizes are 254 $\mathrm{mm}$ and $330.2 \mathrm{~mm}$. Because the $254 \mathrm{~mm}$ is small, it may not be convenient for the steering column layout and may cause stress of the lower arm, therefore, the $330.2 \mathrm{~mm}$ rim is selected. According to the rim size, the selected tire model is type 205/510R13.

FSAE racing requires that cars wheelbase is not less than $1525 \mathrm{~mm}$, since the increased wheelbase directly increases the vehicle's weight and is not suitable for the lightweight car. After considering the similarities of a racer with a car; the engine position, tire width, and the length of the cross arm were selected. The wheelbase is initially selected as $1720 \mathrm{~mm}$. After determining the wheelbase, the wheel track B is determined by the empirical formula (1):

$\mathrm{B}=\mathrm{kL}$

where, $\mathrm{L}$ is the wheelbase in $\mathrm{mm}$; and $\mathrm{k}$ is the coefficient, ranged from $0.55-0.64$.

The initial track is about $1210 \mathrm{~mm}$. In order to increase the inclination angle stiffness of the suspensions, the wheel track can be increased in a small range to have better lateral stability. The front wheel track is larger than the rear wheel track as it is favorable for fast obstacle avoidance. The original front wheel track is $1240 \mathrm{~mm}$, and the rear wheel track is $1180 \mathrm{~mm}$.

The originally racing car main technology parameters are shown in Table $\mathbf{1 .}$

Table 1. Car technology parameters.

\begin{tabular}{|c|c|}
\hline Parameters/Unit & Value \\
\hline \hline Car length/mm & 2800 \\
Car height $/ \mathrm{mm}$ & 1260 \\
Wheelbase $/ \mathrm{mm}$ & 1720 \\
Front wheel track/mm & 1240 \\
Rear wheel track $/ \mathrm{mm}$ & 1180 \\
Whole quality/kg & 200 \\
Front and rear wheel load ratio & $40: 60$ \\
\hline
\end{tabular}

Offset frequency has great impact on the suspension's performance. High offset frequency leads to hard suspension, enhancing the handling \& stability of the mechanism. Low offset frequency leads to soft suspension, resulting in increased ride comfort. In racing car design, a certain degree of ride comfort can be appropriately sacrificed, therefore, a large offset frequency is selected.
The front suspension offset frequency is $f_{n 1}=2.0 \mathrm{~Hz}$ and the rear one is $f_{n 2}=2.2 \mathrm{~Hz}$. The suspension static deflection is determined by the offset frequency, and the optimum stiffness $K_{R}$ can be calculated by the formula (2):

$f_{n}=\frac{1}{2 \pi} \sqrt{\frac{K_{R}}{m}}$

where, $f_{n}$ is the offset frequency, $\mathrm{Hz}$;

$K_{R}$ is the optimum stiffness, $\mathrm{N} / \mathrm{m}$;

$m$ is the load of the shaft, $\mathrm{kg}$.

The equivalent stiffness of suspension and tire $K_{B}$ can be represented by the formula (3):

$\frac{1}{K_{B}}=\frac{1}{K_{W}}+\frac{1}{K_{T}}$

where, $K_{W}$ is the suspension stiffness, $\mathrm{N} / \mathrm{m}$;

$K_{T}$ is the radial stiffness of the tire, equal to $3 \mathrm{e} 6 \mathrm{~N} / \mathrm{m}$.

From formula (3), the front and rear suspension stiffness was observed to be $16783 \mathrm{~N} / \mathrm{m}$ and $29874 \mathrm{~N} / \mathrm{m}$, respectively.

Spring stiffness and the effective stroke can be determined by the movement ratio, and FOX VAN R type damper is selected as the elastic element. The distance of the upper and low holes is $221 \mathrm{~mm}$, and the maximum expansion amount is $71.18 \mathrm{~mm}$.

Based on the structure of FSAE car, the handling and operating conditions, FSAE car wheel alignment parameters selection is generally carried out within a limited range.

Car wheel alignment parameters have generally negative camber angle with negative toe angle. After comprehensive consideration of various factors, FSAE car wheel alignment parameter values were determined, which are shown in Table 2.

Table 2. Wheel alignment parameters.

\begin{tabular}{|c|c|c|c|c|}
\hline $\begin{array}{c}\text { Alignment } \\
\text { Parameter }\end{array}$ & $\begin{array}{c}\text { Camber } \\
\text { Angle/ }\end{array}$ & $\begin{array}{c}\text { Kingpin } \\
\text { Inclination/ }\end{array}$ & $\begin{array}{c}\text { Caster } \\
\text { Angle/ }\end{array}$ & $\begin{array}{c}\text { Toe } \\
\text { Angle/ }\end{array}$ \\
\hline \hline Front suspension & -1 & 4 & 4 & -1 \\
Rear suspension & -1 & 0 & 0 & 0 \\
\hline
\end{tabular}

Offset frequency is an important parameter in suspension design. Front offset frequency $n_{q}$ and rear $n_{h}$ can be obtained by the formula (4):

$n_{q}=\sqrt{k_{q} / m_{q}} /(2 \pi), n_{h}=\sqrt{k_{h} / m_{h}} /(2 \pi)$

Where,

$k_{q}$ is front suspension stiffness, $\mathrm{N} / \mathrm{m}$;

$k_{h}$ is rear suspension stiffness, $\mathrm{N} / \mathrm{m}$; 
$m_{q}$ is sprung mass of front suspension, $\mathrm{kg}$;

$m_{h}$ is sprung mass of rear suspension, $\mathrm{kg}$.

For FSAE racing car, the main objective is to complete the race, and the requirement of the ride comfort is low and therefore, the selection of the offset frequency is larger than the general cars. The initial front suspension offset frequency is $2.0 \mathrm{~Hz}$, and the rear one is $2.2 \mathrm{~Hz}$.

For the independent suspension, roll angle stiffness can be represented as:

$C_{\varphi}=\frac{1}{2} K_{1}^{\prime} B^{2}$

Where, $\mathrm{B}$ is the wheel track, mm;

$K_{1}^{\prime}$ is the line stiffness of the suspension, $\mathrm{N} / \mathrm{mm}$.

Generally speaking, if the roll angle stiffness is larger, the handling and stability will be better and the corresponding ride comfort will be less. Under the effect of $0.5 \mathrm{~g}$ lateral stiffness, the roll angle should be controlled in the range of $2^{\circ}$ to $5^{\circ}$. The same roll angle stiffness affects the handling and stability, therefore, the rear suspension roll angle stiffness is kept smaller than the front.

When the roll center is high, the roll torque will be smaller, as a result, the body-roll angle decreases accordingly. The roll center being too high can pressurize the wheel track when the body tilts, thus reducing the service life of tires. Because FSAE car chassis is very low, the front suspension roll center is set to $30 \mathrm{~mm}$ and the rear roll center is set to $47 \mathrm{~mm}$.

The trim center of double wishbone typed independent suspension can be obtained by using the method of drawing. The intersection point of the extension of the upper and lower wishbone rotating shafts is the trim center.

In the process of general double wishbone independent suspension design, the low cross arm is longer than the upper cross arm, so that the arrangement of the engine is conducive. In order to ensure the handling and stability, the ratio of the upper and low cross arm length is generally about 1.0. The ratio of front and rear are kept as 0.81 and 0.86 , respectively.

Through the above description and preliminary design calculation, the front and rear suspension parameters are shown in Table 3.

Table 3. Main parameters of suspension.

\begin{tabular}{|l|c|c|}
\hline \multicolumn{1}{|c|}{ Name } & Front Suspension & Rear Suspension \\
\hline \hline Offset frequency/Hz & 2.0 & 2.2 \\
roll center height $/ \mathrm{mm}$ & 29 & 46 \\
Push rod length/ mm & 546 & 495 \\
Upper cross arm length/mm & 401 & 409 \\
Low cross arm length $/ \mathrm{mm}$ & 493 & 475 \\
Free length of the damper/mm & 300 & 310 \\
Kingpin caster angle/ ${ }^{\circ}$ & 4 & 0 \\
Kingpin inclination angle/ ${ }^{\circ}$ & 4 & 0 \\
Toe angle/ ${ }^{\circ}$ & -1.0 & 0 \\
Camber angle/ ${ }^{\circ}$ & -1.0 & -1.0 \\
\hline
\end{tabular}

\section{MODELING AND ASSEMBLY}

The current popular 3D software SolidWorks is used to model and lay the foundation for a sound analysis for follow-up.

Because FSAE car is a rear wheel drive with only front end steering, making the design of the front and rear steering knuckle different. Upper and low bolt holes of the steering knuckle are installed on the outside ball head pins of the upper and lower control arms, respectively, with the bearing hole and the shaft shoulder in the middle. The lower side of knuckle arm is installed on the outside ball pin of steering tie rod and the upper side is the support installed on the brake clamp. Because the rear wheel drive increases the intensity on the beam, two cross arms are designed. Accordingly, there are two mounting points on the upper end of the rear steering knuckle. The column 3D models are shown in Fig. (1).

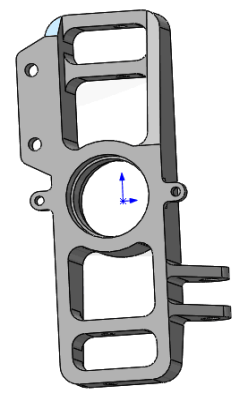

Fig. (1). Front and rear column models.

Control arm is composed of two steel pipe welded by a design angle with a short tube in the welding corner. There is another short small diameter steel tube in this short steel pipe, which are welded together. Low control arm installs the push rod, so above the junction of the two steel pipes, the steel bracket is welded with an open bolt hole in the middle. Because the force of the low control arm is larger, the steel bracket welds at the junctions of suspension control arms. The upper and low control arms are shown in Fig. (2).

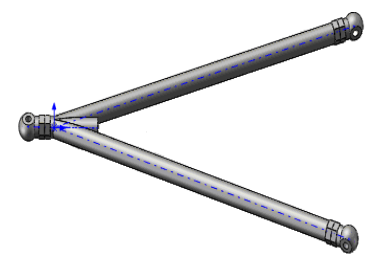

Fig. (2). Upper and low control arm models.

Due to the push rod, anti-roll bar of the front and rear suspension is arranged in a different way, and the shapes of the front and rear rocker arms are also different. Front and rear rocker are four hinged, and the rocker is made by $45 \#$ steel by a wire-cutting process. Front and rear rocker arms are shown in Fig. (3).

Push rod is a steel pipe with a thread at both ends, which connects the ball handle of ball head pin and the rocker arm with the steel bracket of the low cross arm. Both hinged threads are adjusted to change the length of the push rod according to different road conditions, effectively changing the clearance of the car from the ground to make the car in an optimal state. Push rod is shown in Fig. (4). 


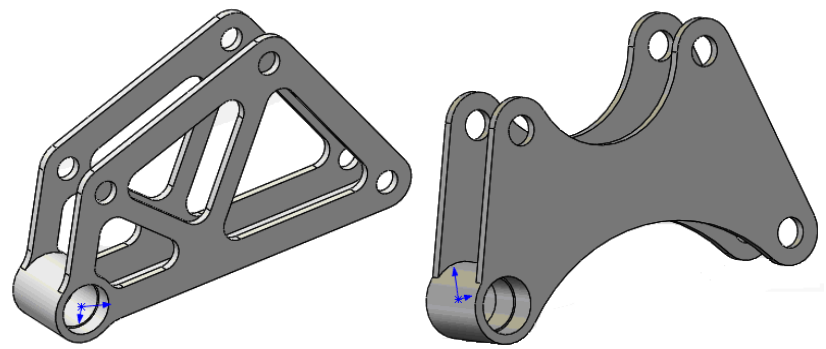

Fig. (3). Front and rear rocker arm models.

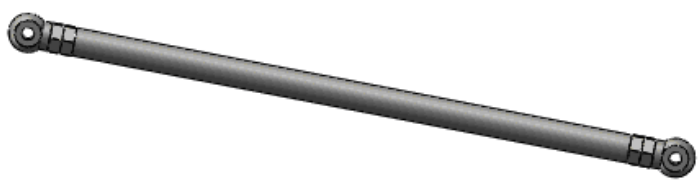

Fig. (4). Push rod model.

Front and rear anti-roll bars are $U$ type. The vertical bar connects with the horizontal bar by the ball head pin and with a replaceable torsion bar, which can be adjusted conveniently for roll stiffness, as shown in Fig. (5).

The tires type is 205/510R13, as shown in Fig. (6).

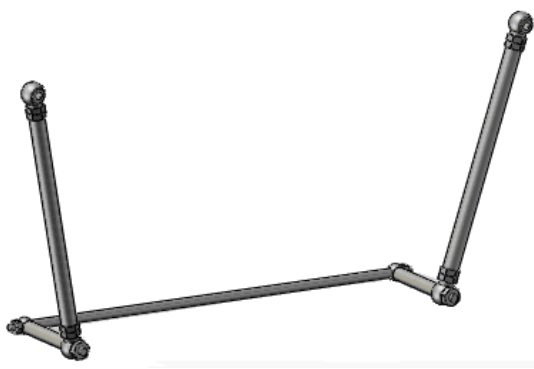

Fig. (5). Anti-roll bar model.

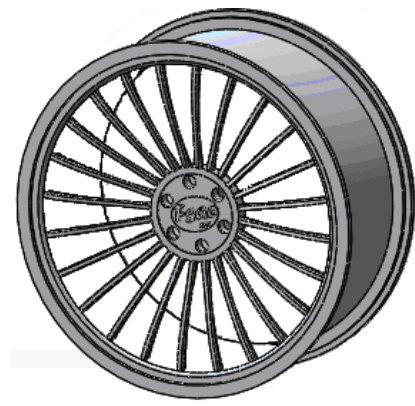

Fig. (6). Wheel rim model.

FOX VAN R type damper is selected for elasticity in the element. The model and real part are shown in Fig. (7).

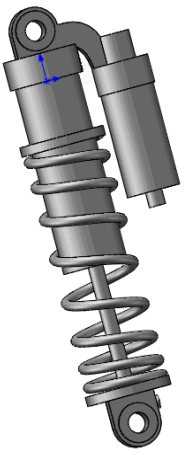

Fig. (7). Model and real picture of damper.
The 3D models of main parts are imported into SolidWorks software to be assembled. Constraints are added between the components to make an assembly. The front and rear suspension 3D assembly models are shown in Figs. (8, 9).

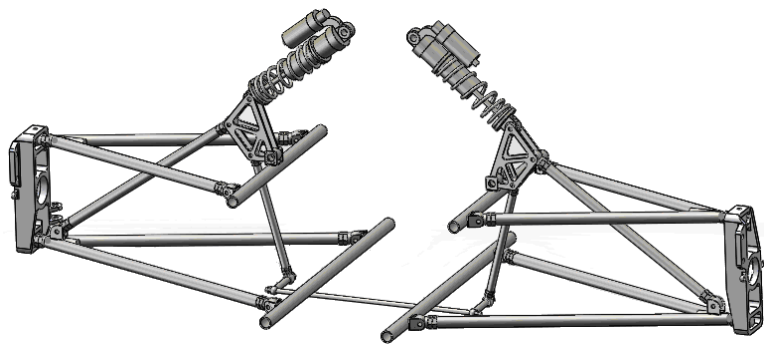

Fig. (8). Front suspension assembly model.

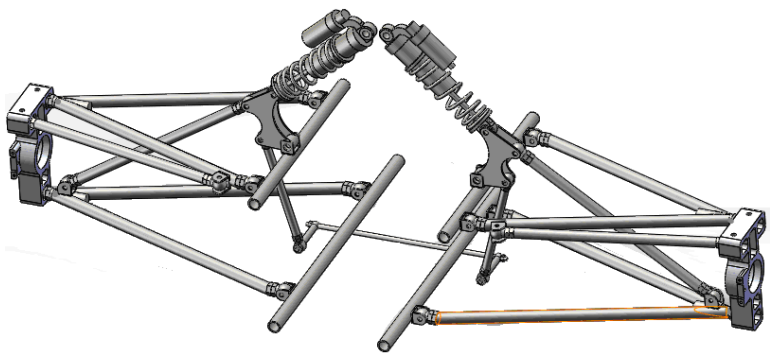

Fig. (9). Rear suspension assembly model.

\section{STRENGTH ANALYSES OF MAIN PARTS}

The force on the rocker arm, support plate of low swimming arm and column can be very large when the suspension starts working, therefore, the strength analysis is performed.

With the Rocker arm material being $45 \#$ steel, and the yield strength being $6.20422 \mathrm{e} 8 \mathrm{~N} / \mathrm{m}^{2}$ before calculating the stress, the maximum stress value is used to simulate the security perspective. The front and rear equivalent stress displacement is shown in Fig. (10).

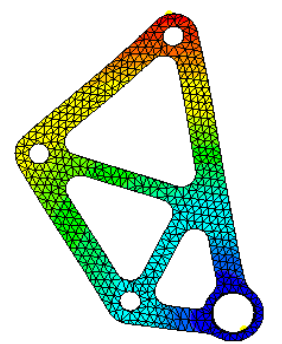

Fig. (10). Equivalent stress displacement of front and rear of the rocker arm.

The maximum displacement of front rocker arm being $4.451 \mathrm{e}-3 \mathrm{~m}$ and the rear one being $3.433 \mathrm{e}-3 \mathrm{~m}$, and the maximum deformation being very smallcan meet the design requirements.

Rocker arm material being $45 \#$ steel, and the yield strength being $5.56402 \mathrm{e} 8 \mathrm{~N} / \mathrm{m}^{2}$, before calculating the stress, the maximum stress value isused to simulate the security perspective, and equivalent stress displacement of low support plate is shown in Fig. (11). The maximum displacement is $1.996 \mathrm{e}-3 \mathrm{~m}$, and the maximum deformation is very small, which can meet the design requirements. 
The column material isaluminum alloy 2024, and the yield strength is $7.58291 \mathrm{e} 7 \mathrm{~N} / \mathrm{m}^{2}$ so before calculating the stress, the maximum stress value is used to simulate front and rear column equivalent stress displacements from the security perspective as shown in Fig. (12). The maximum displacement of front column is $5.802 \mathrm{e}-3 \mathrm{~m}$ and the rear one is $3.766 \mathrm{e}-3 \mathrm{~m}$, and the maximum deformations are very small, which can meet the design requirements.

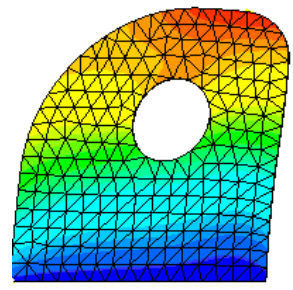

Fig. (11). Equivalent stress displacement of low support plate.

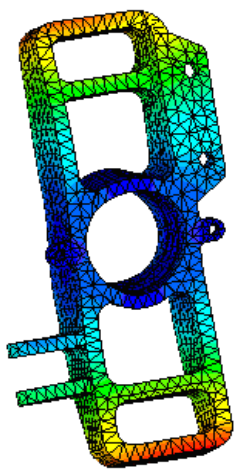

Fig. (12). Equivalent stress displacement of the columns.

\section{CONCLUSION}

In this study, suspension parameters were designed, including wheel alignment parameters, all kinds of stiffness, damping coefficient with cross arm length calculation, etc., and only the main parts were designed and selected.
SolidWorks software was used for modeling and assembly of the suspension's main components. The Simulation Xpress module was used to analyze static stress of FSAE car suspension main mechanical parts, including rocker arms, low support plate and columns. The analysis showed, that the design of FSAE car suspension system can satisfy the performance requirements, which provides the design method and parameters support for building real car model.

\section{CONFLICT OF INTEREST}

The authors confirm that this article content has no conflict of interest.

\section{ACKNOWLEDGEMENTS}

The research was supported by Qing Lan Project, Natural Science Foundation of Jiangsu Province (BK2011405), Natural Science Foundation of the Jiangsu Higher Education Institutions of China (13KJB580001), and Postdoctoral Fund in Jiangsu Province (1402017C).

\section{REFERENCES}

[1] X. Bin, N. Jun, and Z. Lijun, "Suspension structure optimization oriented to crosswind stability of FSAE racing car", Transactions of Beijing Institute of Technology, vol. 32, pp. 694-8, 2012.

[2] W. Jianyu, L. Yutao, and H. Xiangdong, "Optimization of doublewishbone independent suspension for FSAE racing car", Machinery Design \& Manufacture, vol. 10, pp. 120-2, 2011.

[3] N. Limin, Z. Jiekun, and L. Chao, "Structure design of FSAE racing car suspension system", Auto Engineering, vol. 9, pp. 31-4, 2012.

[4] N. Jun, and X. Bin, "Kinematics simulation and optimization of double wishbone front suspension for a FSAE car", Vehicle \& Power Technology, vol. 4, pp. 51-4, 2011.

[5] W. Jun, Z. Shijie, C. Shaojie, and L. Wenshan, "Design of doublewishbone independent suspension of FSAE racing car", Agricultural Equipment \& Vehicle Engineering, vol. 51, pp. 17-20, 2013.

[6] Z. Zhi, D. Min, and L. Chao, "Research on kinematics simulation of front double-wishbone suspension system based on ADAMS", Journal of Liaoning University of Technology (Natural Science Edition), vol. 29, pp. 118-21, 2009.

This is an open access article licensed under the terms of the Creative Commons Attribution Non-Commercial License (http://creativecommons.org/licenses/ by-nc/4.0/) which permits unrestricted, non-commercial use, distribution and reproduction in any medium, provided the work is properly cited. 